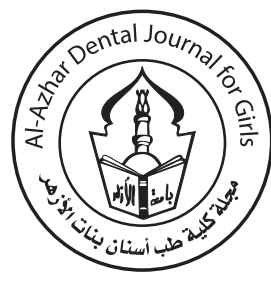

\title{
Effect of Different Chelating Agents on Bond Strength of C-Point Obturating System to Radicular Dentin
}

\author{
Sara E. Abdelaziz ${ }^{1}$, Mervat I. Fawzy ${ }^{2}$, Hagar A. Bastawy ${ }^{3}$
}

Codex : 31/1904

azhardentj@azhar.edu.eg

http://adjg.journals.ekb.eg

DOI: $10.21608 /$ adjg.2019.5991.1039

\section{KEYWORDS}

Chitosan,

Irrigating Solution, CPoint,

EndoSequence BC sealer,

Bond strength.

\begin{abstract}
Purpose: This study was designed to assess the effect of $17 \%$ ethylenediaminetetraacetic acid (17\%EDTA) and $0.2 \%$ Chitosan as chelating agents on bond strength of CPoint obturation system to root canal dentin. Materials and Methods: Fifty extracted lower premolars were selected and prepared using Universal ProTaper rotary files then the samples were equally distributed into 2 main groups depending on the type of the final rinse. Group I:17 \% EDTA, Group II: $0.2 \%$ chitosan, Control group: distilled water. Each main group was further equally distributed into 2 subgroups depending on the type of the filling material. Subgroup A: samples were obturated with gutta-percha and AH Plus sealer. Subgroup B: samples were obturated with CPoint and EndoSeqence $\mathrm{BC}$ sealer. The push out test was carried on using universal testing machine. The sealer penetration inside the dentinal tubules was evaluated using scanning electron microscope (SEM). Results: regarding the results of subgroup A and B, at all levels, the highest value of bond strength was recorded in samples treated with 17\% EDTA, while the lowest value was recorded with the control group and there was no statistical significant difference among the tested groups except for subgroup B at the middle level, there was a statistical significant difference among the tested groups. SEM observation of sealer/ dentin interface revealed few traces of sealer penetration with samples treated with 17\% EDTA. Conclusion: 17\% EDTA when used as final rinse produced higher bond strength with CPoint/EndoSequence BC sealer compared to $0.2 \%$ chitosan, especially at the middle third.
\end{abstract}

- Paper extracted from master thesis entitled "Effect of Different Chelating Agents on Bond Strength of CPoint Obturating System to Radicular Dentin".

1. Demonstrator of Endodontics, Endodontic Department, Faculty of Dental Medicine for Girls, Al -Azhar University. sara. alshaer88@gmail.com

2. Professor of Endodontics, Endodontic Department, Faculty of Dental Medicine for Girls, Al -Azhar University.

3. Associate Professor of Endodontics, Endodontic Department, Faculty of Dental Medicine for Girls, Al -Azhar University. 


\section{INTRODUCTION}

The principal goal of an endodontic filling materials is to tightly seal the root canals and all accessory canals in all dimensions ${ }^{(1)}$. Root canal preparation leaves an amorphous layer of heterogeneous composition, contains both inorganic and organic material, known as the smear layer. This layer spreads on the prepared dentinal walls and plugs the openings of the dentinal tubules. It also prevents the intra-canal medications and sealers from penetrating into the dentinal tubules. Removal both of organic and inorganic components of the smear layer is mandatory to obtain a closely adapted root canal filling materials ${ }^{(2)}$.

Sodium hypochlorite $(\mathrm{NaOCl})$ solution is considered the gold standard because of its exceptional qualities as an antiseptic agent and its tissue dissolving effects. However, it has several disadvantages such as the toxic effect on living tissues at high concentration and remove only the organic part of smear layer, so that a decalcifying agent should be used. Ethylenediamine tetraacetic acid (EDTA) is the most extensively used decalcifying agent, which efficiently removes the smear layer from radicular dentin. However, long time application of EDTA may cause erosion of the peritubular dentin and it also showed limited antimicrobial effect. Moreover, EDTA is not originally found in nature and considered to be a pollutant. Thus, numerous natural agents were introduced to eliminate the smear layer and proposed as an alternative to EDTA ${ }^{(3)}$. Natural products such as chitosan has been introduced. It possesses high chelating affinity for numerous metal ions including Zinc, Cobalt, Iron, Magnesium, and Cupper ions in acid conditions ${ }^{(4)}$.

A preliminary SEM study evaluated the chelating effect of chitosan (as a natural polymer) in comparison with other irrigants on the middle root level after mechanical instrumentation. The results showed that $2 \%$ chitosan acetate was efficient in elimination of the smear layer as 17\% EDTA and the use of $2 \%$ chitosan acetate followed by NaOCL produced clean surface. These results suggested that chitosan is a promising chelating agent ${ }^{(5)}$. The effect of chitosan in different concentrations on the elimination of the smear layer from radicular dentin was evaluated. The results showed that the most efficient concentration and time of chitosan to eliminate the smear layer with little dentin erosion were, $0.2 \%$ and $3 \mathrm{~min}{ }^{(6)}$. A recent study compared the smear layer removal from root canal dentin subjected to two root canal irrigants using ultrasonic; $17 \%$ EDTA and $0.2 \%$ chitosan. The results indicated that $0.2 \%$ chitosan had a greater efficiency in eliminating the smear layer than $17 \%$ EDTA as regards the apical level of the root canal ${ }^{(7)}$.

Gutta-percha with AH plus sealer, which is an epoxy resin-based sealer, has set a gold standard as an obturation system. Despite several advantages exhibited by the system, its hydrophobic nature and its inability to sufficiently reinforce the root canal remain its drawbacks ${ }^{(8)}$. An incipient bioceramic root canal sealer known commercially as EndoSequence BC sealer has been introduced. It has a favorable flowability, small nanoparticle size which enhance its ability to fill any gaps and penetrate the dentinal tubules. The recent advancement in endodontic obturating materials utilizes a hydrophilic polymer in the root canal, the CPoint system. The system consists of premade obturation points formed of polyamide core and outer hydrophilic polymer coating. The points are designed to expand when exposed to water and this hygroscopic expansion occurs in lateral direction without any axial expansion ${ }^{(9,10)}$. These considerable amounts of expansion have taken place with CPoint system which occupies the irregularities and the remaining spaces of the canal, improving the hermetic seal $^{(11-13)}$.

Different methods have been used for assessing the bond strength of root canal sealers to radicular dentin, such as push-out bond strength test ${ }^{(14,15)}$. Therefore, the aim of the current study was directed to compare the effect of $17 \%$ EDTA and $0.2 \%$ chitosan as chelating agents on the bond strength of the obturating system (CPoint/EndoSequence BC sealer). 


\section{MATERIALS AND METHODS}

\section{Teeth selection and preparation:}

Fifty recently extracted human single rooted lower premolars with single canal, completely formed roots and no evidence of fractures or cracks were selected. The teeth were rinsed under tap water to remove tissues, blood and debris then kept until use in distilled water. Each tooth was decapitated at the cemento-enamel junction (CEJ) using diamond disc (Diatech, Goltène AG,Altstätten, Switzerland) under steady water cooling. The root lengths of all teeth were $15 \mathrm{~mm}$. Canal patency was done by \#10 K-files (MANI Inc., Japan) and the working length was measured by subtracting $1 \mathrm{~mm}$ from length when the tips of \#10 K-file became observed at the apical foramen.

ProTaper Universal rotary NiTi files (Dentsply, Maillfer, Switzerland) were used in a crown-down manner for root canal preparation with torque and speed adjusted according to manufacturers' recommendations for each file used. A set of six instruments were used (SX, S1, S2, F1, F2, and F3), the first three files were used for coronal $2 / 3$ preparation and the other three files were used for apical preparation. After each instrument use, irrigation was done with a fresh preparation of 2 $\mathrm{ml} 2.6 \% \mathrm{NaOCl}$ solution for 1 minute dispensed through a 31gauge side vent irrigating needle, where the needle was inserted deeply inside the root canal without binding.

\section{Preparation of chitosan solution:}

Preparation of $0.2 \%$ chitosan acetate solutions was performed using $0.2 \mathrm{~g}$ chitosan powder (Sigma Co., Egypt), diluted in $100 \mathrm{ml}$ of $1 \%$ acetic acid (Alpha Chemika,India), then the mixture was agitated using a magnetic stirrer [78HW1,ZenithLab(Jiangsu) Co.,Ltd, China] for $2 \mathrm{~h}$. The solution was saved in the refrigerator and used within two weeks after preparation ${ }^{(16)}$.

\section{Samples grouping:}

After root canal preparation, the samples were equally distributed into two experimental groups (I, II) (20 samples each) according to the final rinse used and control group (10 samples). Group I: samples were irrigated with 17\% EDTA (Prevest Denpro limited, Digiana, Jammu, India). Group II: samples were irrigated with $0.2 \%$ chitosan acetate. Control group: samples were irrigated with distilled water (Ostuka pharm, Egypt), each group was irrigated using $5 \mathrm{ml}$ of the irrigant for 3 minutes $(6,17)$. Then all samples were received $5 \mathrm{ml}$ of distilled water and dried by utilizing paper points. Each group was further equally distributed into two subgroups depending on the filling material; subgroup A: samples were obturated with gutta-percha/AH Plus sealer (Dentsply DeTrey, Konstanz, Germany) and subgroup B: samples were obturated with CPoint/ EndoSeqence BC sealer (EndoTechnologies, Shrewsbury, MA, USA), (Brasseler, Savannah,GA, USA).

\section{Samples obturation:}

\section{Subgroup A (Gutta-percha /AH Plus sealer):}

The samples were filled with ProTaper guttapercha cones (\#F3) and AH Plus sealer which was mixed according to manufacturers' instructions. The canal walls were coated with sealer where, the sealer was added on the master cone which moved vertically up and down inside the canal to coat the canal wall completely by the sealer. Root canal filling was done using cold lateral compaction technique using \#25 finger spreader and adding accessory cones (\#25, 0.02 taper). The excess guttapercha was seared off using hot instrument, then the access cavity was filled with a temporary filling.

\section{Subgroup B (CPoint/EndoSequence BC sealer):}

The samples were filled with CPoint cones (\#F3) and EndoSequence BC sealer was injected in the canal lumen from a pre-mixed syringe using 
its disposable tip following the manufacturers' recommendations. The canal walls were coated with sealer where, and the master cone moved vertically up and down inside the canal to ensure full coating of the canal wall by the sealer. Root canal filling was done using single cone technique according to manufacturers' instructions. The excess CPoint was sheared off to the level of the canal orifice using a hand-piece at high speed and a cylindrical diamond stone without water, then the access cavity was filled with temporary filling.

Storage of all samples at $37^{\circ} \mathrm{c}$ in $100 \%$ humidity for 48 hours was done to guarantee full setting of the sealer.

\section{Samples preparation for push-out bond strength testing:}

Isomet 4000 microsaw (Buehler, USA) was used to section the samples perpendicular to the root's long axis without water coolant, where three $2 \mathrm{~mm}$-thickness sections were gained from coronal, middle and apical levels of each sample. Indelible marker was used to mark the apical surface of each section, then the sections were kept in $100 \%$ humidity till testing.

Cylindrical stainless-steel plunger with diameter $0.9,0.7$ and $0.5 \mathrm{~mm}$ corresponding to coronal, middle and apical sections respectively used to load root filling of each section. The tip of the plunger was adjusted to cover the root filling material without contacting the canal wall. The plunger was connected to the universal testing machine (Instron, Norwood, MA, USA) and the applied load was directed from apical aspect to coronal aspect in order to avoid any impediments during the push-out testing because of tapering of the root canal. A cross-head speed of 0.5 $\mathrm{mm} / \mathrm{min}$ was conducted until debonding happened and the maximum load conducted for debonding was measured in Newton $(\mathrm{N})$.

The push out bond strength value in mega-pascal (MPa) for each sample was calculated using the following equation:

\section{Push-out bond strength $(\mathrm{MPa})=$}

Maximum load (N)

Adhesion area of root canal filling $\left(\mathrm{mm}^{2}\right)$

\section{Area of root canal filling $\left(\mathrm{mm}^{2}\right)=$}

(Circumference of coronal aspect + circumfer-

ence of apical aspec) $\times$ thickness of the section

2

\section{SEM evaluation:}

After the push-out test, two selected sections from each group were grooved longitudinally in buccolingual direction without reaching the internal portion of the canal and sectioned with sharp chisel. The sections were coated with gold and examined under SEM (FEI company, Nertherland). Under magnifications (X 2000 and X 4000), a two photomicrographs were obtained to evaluate the amount of sealer penetrating the dentinal tubules.

\section{Statistical analysis:}

Tests of normality (Kolmogorov-Smirnov and Shapiro-Wilk tests) were used to explore the normality of the numerical data and to check the distribution of data. Data were presented as median and range. For non- parametric data Mann-Whitney $\mathrm{U}$ test was used to compare between the two filling materials. Kruskal-Wallis test was used to compare between irrigants. Friedman's test was used to compare between root levels. Dunn's test was used for pair-wise comparisons. The significance level was set at $\mathrm{P} \leq 0.05$. IBM SPSS Statistics Version 20 for Windows was utilized to carry out statistical analysis.

\section{RESULTS}

I. Push out test results:

Comparison of bond strength between the tested chelating agents at each root level: (Table 1) and (Fig. 1) 
Table (1): The median and range of the bond strength comparing the tested chelating agents and control group within each subgroup at the three root canal levels (coronal, middle and apical).

\begin{tabular}{|c|c|c|c|c|c|c|c|c|}
\hline \multirow[t]{2}{*}{ Filling material } & \multirow[t]{2}{*}{ Root level } & \multicolumn{2}{|c|}{$\begin{array}{c}\text { Group I } \\
\text { (17\%EDTA) }\end{array}$} & \multicolumn{2}{|c|}{ Group II $(0.2 \%$ chitosan $)$} & \multicolumn{2}{|c|}{$\begin{array}{l}\text { Control group } \\
\text { (Distilled water) }\end{array}$} & \multirow[t]{2}{*}{$P$-value } \\
\hline & & Median & Range & Median & Range & Median & Range & \\
\hline \multirow{4}{*}{$\begin{array}{c}\text { Subgroup A } \\
\text { (Gutta-percha/AH } \\
\text { Plus sealer) }\end{array}$} & Coronal & 4.92 & $2.24-11.52$ & 3.53 & $1.29-6.83$ & 1.85 & $1.23-5.01$ & 0.053 \\
\hline & Middle & 5.12 & $1.36-8.17$ & 3.69 & $0.50-9.52$ & 2.33 & $1.62-8.15$ & 0.175 \\
\hline & Apical & 3.46 & $1.74-5.90$ & 2.54 & $1.18-4.90$ & 1.73 & $1.49-6.96$ & 0.263 \\
\hline & Total & 4.27 & $2.65-8.53$ & 3.25 & $1.46-6.31$ & 2.57 & $1.83-4.68$ & 0.071 \\
\hline \multirow{4}{*}{$\begin{array}{c}\text { Subgroup B } \\
\text { (CPoint / } \\
\text { EndoSequence BC } \\
\text { sealer) }\end{array}$} & Coronal & 2.35 & $0.17-9.63$ & 0.63 & $0.14-2.32$ & 0.69 & $0.32-2.38$ & 0.092 \\
\hline & Middle & $1.21^{\mathrm{A}}$ & $0.63-2.07$ & $0.65^{\mathrm{B}}$ & $0.06-1.33$ & $0.54^{\mathrm{B}}$ & $0.02-1.00$ & $0.020 *$ \\
\hline & Apical & 1.52 & $0.03-2.15$ & 0.30 & $0.16-2.07$ & 0.32 & $0.05-2.40$ & 0.114 \\
\hline & Total & $1.68^{\mathrm{A}}$ & $0.78-4.43$ & $0.73^{\text {в }}$ & $0.21-1.33$ & $0.67^{\text {в }}$ & $0.46-1.25$ & $0.002 *$ \\
\hline
\end{tabular}

*: Significant at $P \leq 0.05$, Different superscripts in the same row indicate statistically significant difference.

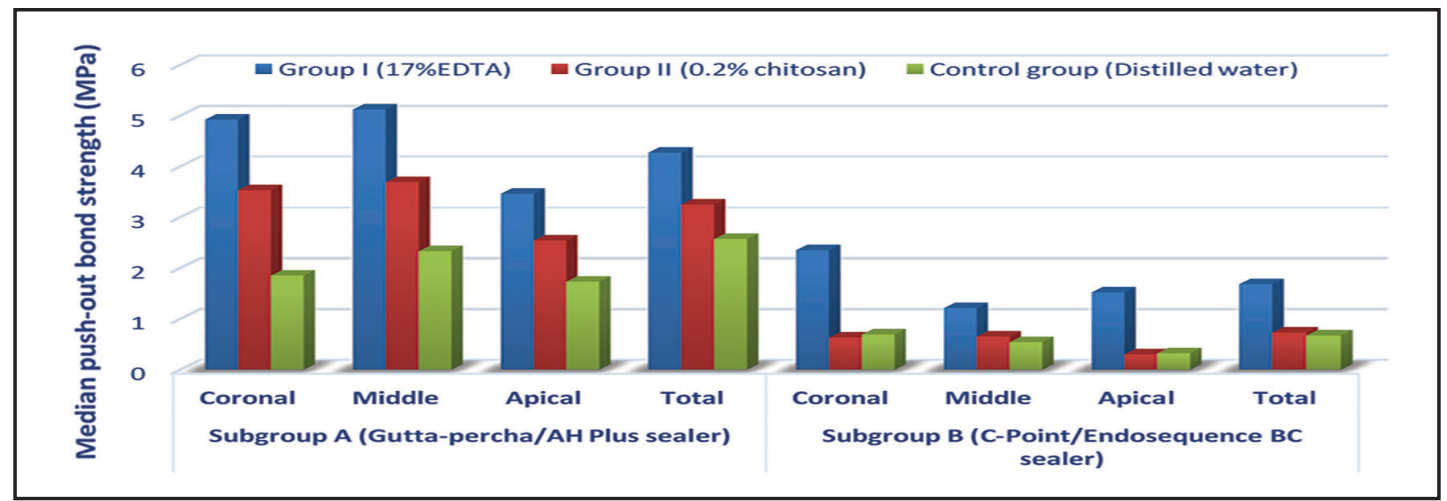

Figure (1): A bar chart comparing the median push out bond strength among 17\% EDTA, 0.2\% chitosan and distilled water (control) within each subgroup at the coronal, middle and apical root canal levels.

\section{Subgroup A (Gutta-percha /AH Plus sealer):}

At all levels, the difference among the tested irrigants was not statistically significant $(\mathrm{P}>0.05)$

\section{Subgroup B (CPoint / EndoSequence BC sealer):}

At the coronal level and the apical level, the difference among the tested irrigants was not statistically significant $(\mathrm{P}>0.05)$. At the middle level, the difference among the tested irrigants was statistically significant $(\mathrm{P} \leq 0.05)$.

\section{Comparison of push out bond strength between the tested filling materials at each root level:}

Group I (17\% EDTA):

The difference between the two filling materials at the coronal, middle and apical levels was statistically significant, where the higher value of the bond strength was showed in samples obturated with gutta-percha and AH Plus sealer $(\mathrm{P} \leq 0.05)$. 


\section{Group II ( $0.2 \%$ chitosan):}

The difference between the two filling materials at the coronal, middle and apical levels was statistically significant, where the higher value of the bond strength was showed in samples obturated with gutta-percha and AH Plus sealer $(\mathrm{P} \leq 0.05)$.

\section{Control group (distilled water):}

The difference between the two filling materials at the coronal level and the apical level was not statistically significant, where the higher value of the bond strength was showed in samples obturated with gutta-percha and AH Plus sealer $(\mathrm{P}>0.05)$, however, the difference was statistically significant between the two filling materials at the middle level $(\mathrm{P} \leq 0.05)$

\section{Comparison of push out bond strength among the root levels within each group:}

\section{Subgroup A (Gutta-percha /AH Plus):}

In group I (17\% EDTA), the difference among the three root levels was statistically significant
$(\mathrm{P} \leq 0.05)$. While in group II $(0.2 \%$ chitosan $)$ and control group (distilled water) the difference was not statistically significant $(\mathrm{P}>0.05)$.

\section{Subgroup B (CPoint / EndoSequence BC sealer):}

the difference among the three root levels was not statistically significant irrespective the final rinse used $(\mathrm{P}>0.05)$.

\section{Scanning electron microscopic results:}

\section{Group I (17\% EDTA):}

Tracing the interface revealed that, both subgroup A and subgroup B showed few traces of sealer particles penetrating dentinal tubules at the coronal level and the middle level, however, at the apical level there was no evidence of sealer penetration. (Fig. 2)

\section{Group II (0.2\% chitosan):}

Tracing the interface revealed no sealer particles penetrating dentinal tubules at the coronal, middle and apical levels in subgroup A and subgroup B. (Fig. 3)
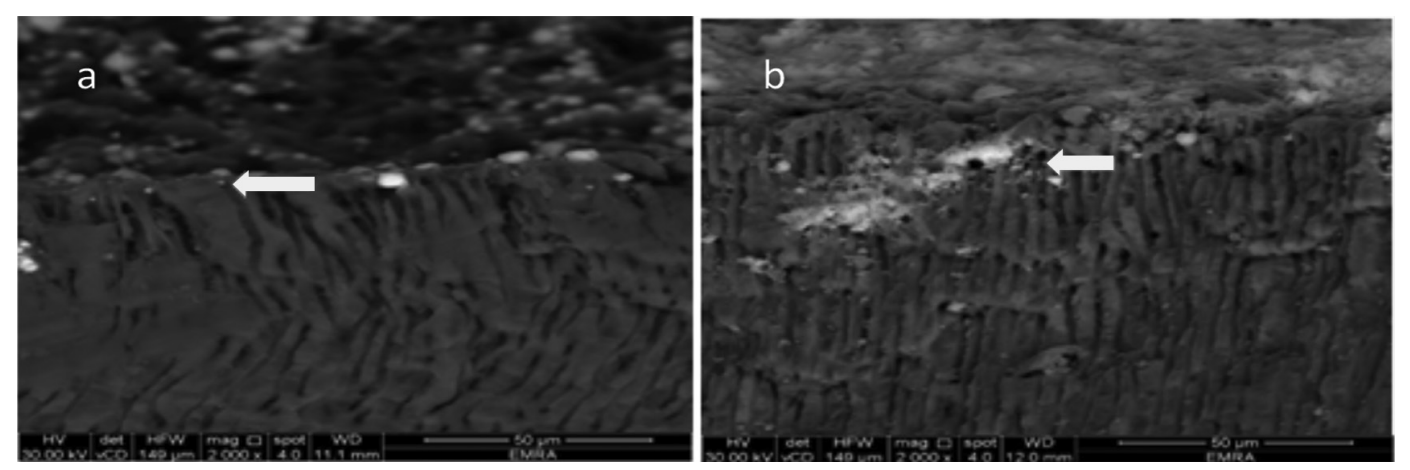

Figure (2): A scanning photomicrograph of sealer/dentin interface at the coronal level of samples rinsed with 17\% EDTA showing few traces of sealer particles penetrating dentinal tubules, a) gutta-percha /AH Plus sealer, b) CPoint/EndoSequence BC sealer (X2000). 


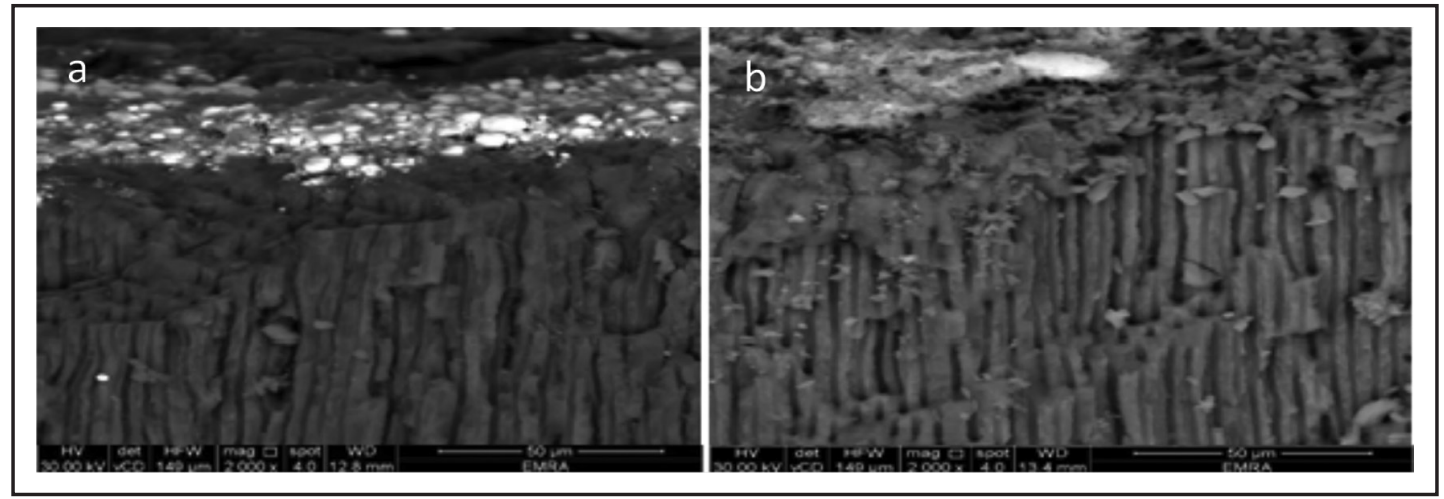

Figure (3): A scanning photomicrograph of sealer/dentin interface at the coronal level of samples rinsed with $0.2 \%$ chitosan showing no of sealer particles penetrating dentinal tubules, a) gutta-percha /AH Plus sealer, b) CPoint/EndoSequence BC sealer (X2000).

\section{DISCUSSION}

The presence of anatomic ramifications of the root canal has advocated the evolution of different obturating materials and techniques to achieve the desired fluid tight hermetic seal. A number of variables, including the keeping or removing of the smear layer, surface tension of the sealers, wetting capability and intermolecular surface energy of the dentin structure may affect adhesion properties ${ }^{(1,18)}$.

The use of new irrigating solutions and obturating systems clinically must be firstly tried with in-vitro studies which evaluate the beneficial effects and sequela on human beings. Therefore, the target of the ongoing study was directed to evaluate the effect of $17 \%$ EDTA and $0.2 \%$ chitosan as chelating agents on bond strength of the new filling system (CPoint/EndoSequence BC sealer).

The higher bond strength results of guttapercha and AH Plus sealer recorded with the use of $17 \%$ EDTA could be attributed to the higher demineralization effect of EDTA which expose more collagen, where the adhesion of AH Plus sealer to dentin depends on bonding between the open epoxy rings in the sealer with the exposed amine groups on collagen (organic part of the dentin) forming a covalent bond, rather than micromechanical retention through the resin tags penetration into the tubule ${ }^{(19)}$.
The efficiency of chitosan as chelating agent could be explained by the fact that, chitosan is hydrophilic in nature which favors its intimate contact with root canal dentin and its adsorption to root canal wall. Additionally, it has many free amino and hydroxyl groups that make it cationic in nature which promotes the ionic interaction between the calcium ions in dentin and the chelator ${ }^{(20)}$.

In the current study, the results are comparable to that obtained with previous study, in which EDTA produced higher push out bond strength results ${ }^{(21,}$ ${ }^{22)}$. In contrast, the results are in disagreement with pervious study which showed that the highest mean push out bond strength of AH Plus sealer recorded using $0.2 \%$ chitosan compared to $17 \%$ EDTA and Qmix ${ }^{(23)}$. This could be attributed to the use of different methodology, where the samples were immersed for $3 \mathrm{~min}$ in a solution of 17\% EDTA followed by $5.25 \% \mathrm{NaOCl}$ for the same duration. $\mathrm{NaOCl}$ can directly erode the collagen previously exposed by the demineralizing agent (24). The lowest push out bond strength results recorded with distilled water are in agreement with previous study stated that the use of chelating solutions enhanced the bond strength of AH Plus sealer ${ }^{(25)}$.

The statistically significant higher median push out bond strength results of subgroup B(CPoint/ EndoSequence BC sealer) recorded with $17 \%$ 
EDTA at the middle third could be attributed to its smaller canal diameter compared to the coronal third, where the moisture and dihydrogen monoxide present within the instrumented canals form a hydrogen bond with the existing polar locations of CPoint, thus causing lateral enlargement inside the polymeric chains, which increased the adaptability of the hydrophilic CPoint/ EndoSequence BC sealer ${ }^{(11)}$. In contrast to the current study, it has been reported that the existence or absence of smear layer did not affect significantly on the push out bond strength of gutta-percha/EndoSequence BC Sealer. These controversial results could be attributed to using $17 \%$ EDTA with less contact time $(1 \mathrm{~min})^{(26)}$.

The higher results of push out bond strength regarding gutta-percha and AH Plus sealer might be attributed to the covalent bond formed between the amino groups present in collagen and the open epoxy rings in the sealer. Moreover, epoxy-based resin sealer penetrates deeper into the dentinal tubules due to its high flow and long-term polymerization time, which might assist in improving the mechanical interlocking between the dentin and sealer ${ }^{(27)}$. On the other side, the lower values of push out bond strength of CPoint/ EndoSequenceBC sealer could be related to the composition of $\mathrm{BC}$ sealer which chemically bonds with the inorganic phase of dentin, while the chelating efficiency of the tested chelating agents depends on withdrawal of calcium ions in dentin ${ }^{(28)}$.

The results of the previous studies reported that the highest bond strength value was recorded in root canals filled with CPoint and BC sealer, whereas the lowest value was noticed in canals filled with gutta-percha and AH Plus sealer which is in disagreement with the results of the current study ${ }^{(29,30)}$. This might be attributed to the use of larger tip diameter of CPoint, where in larger sizes of CPoint, there was higher amount of polymer, higher lateral expansion, which decrease gaps and enhance sealer penetration and adaptation in dentin ${ }^{(10,31)}$. Another recent study was inconsistent with the present study ${ }^{(32)}$, this could be related to the use of single cone technique with (gutta-perch/AH Plus), where it has been reported that, the lateral compaction technique showed significant higher results in comparison with single cone technique ${ }^{(33)}$.

The highest bond strength results of guttapercha and AH Plus sealer, was recorded at the middle level irrespective to the final rinse used. This could be clarified by the fact that the accessibility of root canal to the instruments and irrigants at the coronal and middle thirds is easier and greater than at the apical level, coupled with larger diameter of dentinal tubules orifices that allowed better circling and enhanced action of the irrigants, making efficient removal of the smear layer predictable ${ }^{(34)}$. Moreover, this is probably due to the crown-down manner used with ProTaper Universal rotary files, where the shaping files (SX, S1 and S2) are used to $2 / 3$ of WL according to the manufacture instruction, in addition to the instrument design which facilitates upward removal of generated dentin debris. In addition, stagnation of residual fluid in the middle level where the needle was inserted deeply into the canal (approximately at the junction between middle and apical thirds).

The lower mean push out bond strength that was recorded at the apical level in samples treated with $17 \%$ EDTA and $0.2 \%$ chitosan might be attributed to the increased dentin sclerosis in the apical region with less content of collagen fibers to which AH Plus sealer bond ${ }^{(35)}$. These results were in disagreement with pervious study which reported that the highest mean bond strength of AH Plus sealer recorded at the apical level was comparable to that of the coronal and middle levels when using 17\% EDTA as final irrigating solution ${ }^{(36)}$. This divergence in results could be explained by difference in the obturating technique, where they used Element Obturation unit. Moreover, recent study reported that the apical third showed significantly higher push-out bond strength value followed by cervical and middle ${ }^{(37)}$. This could be attributed to the use of EndoVac irrigation system. 
The highest bond strength results of subgroup B (CPoint/EndoSequence BC sealer), were recorded at the coronal level in samples irrigated with $17 \%$ EDTA or distilled water, and at the middle level in samples irrigated with $0.2 \%$ chitosan. The higher results in the middle level with $0.2 \%$ chitosan could be attributed to the better accessibility of the instruments and circulation of irrigating solution as mentioned previously, however, higher results reported with 17\% EDTA at the coronal level may be attributed to the higher number of dentinal tubules and surface area. That provided a higher amount of calcium nescssary to EndoSequence BC sealer in bonding with dentin ${ }^{(28,38)}$. These results are supported by another one evaluated the influence of EndoSequence-BC-Sealer on bond strength to root dentin, in comparison with AH-Plus with different obturation techniques, where the coronal root level of all groups showed the highest mean bond strength values ${ }^{(39)}$.

In the present study, SEM observation of sealer/ dentin interface of tested samples which were treated with $17 \%$ EDTA revealed that there was few traces of sealer penetrating into the dentinal tubules, however, samples treated with $0.2 \%$ chitosan showed no sealer penetration. This may be attributed to the viscosity of EDTA which was lower than that of $0.2 \%$ chitosan, so $17 \%$ EDTA could penetrate into dentinal tubules removing smear plugs, and thus permitting the penetration of the sealers.

\section{CONCLUSION}

- The innovated system (CPoint/EndoSequence sealer) did not result in higher bonding to the radicular dentin in comparison to gutta-percha and AH Plus sealer.

- The effect of $0.2 \%$ chitosan on the bonding of gutta-percha and AH Plus sealer to the radicular dentin was comparable to that of $17 \%$ EDTA.

- CPoint/EndoSequence sealer revealed higher bonding results with radicular dentin when $17 \%$ EDTA used as a final rinse compared to $0.2 \%$ chitosan, especially at the middle third.

\section{REFERENCES}

- $\quad$ Braga RR, Meira JB, Boaro LC, Xavier TA. Adhesion to tooth structure: a critical review of "macro" test methods. Dent Mater 2010; 26:38-49.

- Shahvaran A, Haghdoost AA, Adl A, Rahimi H, Shadifar F. Effect of smear layer on sealing ability of canal obturation: a systematic review and meta-analysis. J Endod 2007; 33:96-105.

- Mozayeni MA, Zadeh YM, Paymanpour P, Ashraf H, Mozayani M. Evaluation of push-out bond strength of AH26 sealer using MTAD and combination of $\mathrm{NaOCl}$ and EDTA as final irrigation. Dent Res J 2013; 10: 359-63.

- Pimenta JA, Zaparolli D, Pecora JD, Cruz-Filho AM. Chitosan: effect of a new chelating agent on the microhardness of root dentin. Braz. Dent J 2012; 23:212-7.

- $\quad$ Fawzy MI. Scanning electron microscopic evaluation of the effectiveness of chitosan solution in smear layer removal. Egy dent J 2011; 57:419-24.

- $\quad$ Silva PV, Guedes DF, Pécora JD, Cruz-Filho AM. Timedependent effects of chitosan on dentin structures. Braz dent J 2012; 23: 357-61.

- Kamble AB, Abraham S, Mehta DL. Scanning electron microscopic evaluation of efficacy of $17 \%$ ethylenediaminetet-raacetic acid and chitosan for smear layer removal with ultrasonics: an in vitro study. Contemp clin dent 2017; 8: 621-26.

- Leduc $\mathbf{J}$ and Fishelberg G. Endodontic obturation: a review. Gen Dent 2003; 51: 232-3.

- EndoTechnologies, LLC, Shrewsbury, MA, 1-5 Lakeview Avenue Shrewsbury, MA 01545, USA.

- Didato A, Eid AA, Levin M, Khan S, Tay FR, Rueggeberg FA.Time-based lateral hygroscopic expansion of a waterexpandable endodontic obturation point. J Dent 2013; 41:796-801.

- Hegde V and Murkey LS. Microgap Evaluation of Novel Hydrophilic and Hydrophobic Obturating System. J Clinc Diag Res 2017; 11:75-8.

- $\quad$ El Sayed MA, Al Husseini H. Apical dye leakage of two single-cone root canal core materials (hydrophilic core material and gutta-percha) sealed by different types of endodontic sealers: An in vitro study. J Conserv Dent 2018; 21:147-52.

- $\quad$ Sinhal TM, Shah RP, Jais PS, Shah NC, Hadwani KD, et al. An in vitro comparison and evaluation of sealing ability of newly introduced CPoint system, cold lateral condensation, and thermoplasticized gutta-percha obturating technique: A dye extraction study. Contemp Clin Dent 2018; 9:164-9. 
- Thompson JI, Gregson PJ, Revell PA. Analysis of pushout test data based on interfacial fracture energy. J Mat Sci 1999; 10:863-8.

- Chandra N and Ghonem H. Interfacial mechanics of pushout tests: theory and experiments. Composites Part A: App Sci Manuf 2001; 32:575-84.

- Da cruz-Filho AM, De Vito Bordin AR, Souza-Flamini LE, Da costa Guedes DF, Saquy PC, et al. Analysis of the shelf life of chitosan stored in different types of packing, using colorimetry and dentin microhardness. Restor dent endod 2017; 42: 87-94.

- Mello I, Kammerer BA, Yoshimoto D, Macedo MC, Antoniazzi JH. Influence of final rinse technique on ability of ethylenediamine-tetraacetic acid of removing smear layer. J endod 2010; 36:512-4.

- Kwang-Won Lee MC, Williams BS and Camps JC, Pashley DH. Adhesion of endodontic sealers to dentin and gutta-percha. J Endod 2002; 10:684-8.

- Neelakantan P, Varughese AA, Sharma S, Subbarao CV, Zehnder M, et al. Continuous chelation irrigation improves the adhesion of epoxy resin-based root canal sealer to root dentin. Int Endod J 2012; 45:1097-102.

- Zhang J, Xia Z, Liu P, Cheng Q, Tahirou T, et al. Chitosan modification and pharmaceutical/biomedical applications. Mar Drugs J 2010; 8:1962-87.

- Molinos E, Berástegui E, Ortega J. To Comparison of Standard and New Chelating Solutions in Endodontics. J Dental Sci 2017; 2:1-8.

- Thota MM, Sudha K, Malini DL, Madhavi SB. Effect of different irrigating solutions on depth of penetration of sealer into dentinal tubules: A confocal microscopic study. Contemp Clin Dent 2017; 8:391-4.

- Bayram HM, Bayram E, Kanber M, Celikten B, Saklar F. Effect of different chelating solutions on the push-out bond strength of various root canal sealers. Biomed Res India J 2017:1-6.

- Qian W, Shen Y, Haapasalo M. Quantitative analysis of the effect of irrigant solution sequences on dentin erosion. J Endod. 2011; 37:1437-41.

- Tuncel P, Nagas M, Cehreli Z, Uyanik O, Vallittu P, et al. Effect of endodontic chelating solutions on the bond strength of endodontic sealers. Braz Oral Res 2015; 29:1-6.

- Shokouhinejad N, Gorjestani H, Nasseh A, Hoseini A, Mohammadi M, et al. Push-out bond strength of guttapercha with a new bioceramic sealer in the presence or absence of smear layer. Aust Endod J 2013; 3:1-6.

- Oksan T, Aktener BO, Sen BH, Tezel H. The penetration of root canal sealers into dentinal tubules. A scanning electron microscopic study. Int Endod J 1993 26:301-5.
- Carvalho CN, Soares RG, Candeiro GT, Martinez LG, de Souza JP, et al. Micro push-out bond strength and bioactivity analysis of a bioceramic root canal sealer. Iran Endod J 2017; 12: 343-8.

- Pawar AM, Pawar S, Kfir A, Pawar M, Kokate S. Pushout bond strength of root fillings made with CPoint and $\mathrm{BC}$ sealer versus gutta-percha and $\mathrm{AH}$ Plus after the instrumentation of oval canals with the Self-Adjusting File versus WaveOne. Int Endod J 2016; 49:374-81.

- Hassan N, Diab A,Ahmed G. Bond Degradation Resistance and Interface Characterization of a Water-Expandable Endodontic Obturation Point. M J Dent 2016; 1:1-8.

- Wan LS, Xu ZK, Huang XJ, Wang ZG, Ye P. Hemocompatibility of poly (acrylonitrile-co-N-vinyl2-pyrrolidone): swelling behavior and water states. Macro Biosci 2005; 5:229-36.

- $\quad$ Kumar KN, Kumar MP, Rao PSS, Pallavi V, Ahmed S. Comparative Evaluation of Push-out Bond Strength of Novel Smart Seal System with Resilon/Epiphany and Gutta-percha/Ah-plus Obturating System: An in vitro Study. Int J Sci Stud 2016; 4:114-7.

- Mokhtari H, Rahimi S, Reyhani MF, Galledar S, Zonouzi HR. Comparison of Push-out Bond Strength of Guttapercha to Root Canal Dentin in Single-cone and Cold Lateral Compaction Techniques with AH Plus Sealer in Mandibular Premolars. JODDD 2015; 9: 221-5.

- Canderio GTM, Matos IB, Costa CFE, Fonteles CSR, Vale MS. A comparative scanning electron microscopy evaluation of smear layer removal with apple vinegar and sodium hypochlorite associated with EDTA. J Appl Oral Sci 2011; 19:639-43.

- $\quad$ Kim YK, Grandini S, Ames JM, Gu LS, Kim SK, Pashley $\mathrm{DH}$, et al. Critical review on methacrylate resin-based root canal sealers. J Endod 2010; 36:383-99.

- Balguerie E, van der Sluis L, Vallaeys K, GurgelGeorgelin M, Diemer F. Sealer penetration and adaptation in the dentinal tubules: a scanning electron microscopic study. J Endod. 2011;37:1576-9.

- Verma D, Taneja S, Kumari M. Efficacy of different irrigation regimes on the push-out bond strength of various resin-based sealers at different root levels: An in vitro study. J Conserv Dent 2018;21:125-9.

- Mjor IA and Nordahl I. The density and branching of dentinal tubules in human teeth. Arch Oral Biol 1996; 41: 401-12.

- $\quad$ Dabaj P, Kalender A, Eldeniz A. Push-Out Bond Strength and SEM Evaluation in Roots Filled with Two Different Techniques Using New and Conventional Sealers. Materials 2018; 11: 1620 -30. 